Session No. 2366

\title{
MULTI-DISCIPLINARY TEACHING AND LEARNING IN A SENIOR PROJECT COURSE
}

\author{
Michael W. Ellis \\ Department of Mechanical Engineering \\ Virginia Polytechnic Institute and State University \\ Blacksburg, VA 24060
}

\begin{abstract}
Multi-disciplinary team projects provide students with an opportunity to expand not only their knowledge, but also their approach to design. This paper reviews teaching and student learning in a multi-disciplinary senior design project in which a team of mechanical engineering students worked with students from architecture, industrial design, and building construction to design and build a grid independent solar house. The solar house competed with thirteen other schools in the Department of Energy's Solar Decathlon design competition.

The course objectives, structure, and evaluation methods are described. Results from a survey suggest that the course helped students to develop teamwork and communication skills. Further, through interaction with students from a very different educational background, the engineering students developed a deeper understanding of their own approach to design as well as an appreciation for alternative approaches.
\end{abstract}

\section{INTRODUCTION}

Capstone courses in which students participate in a design project are an accepted part of the engineering curriculum at most schools ${ }^{1}$. In the Department of Mechanical Engineering at Virginia Tech, the capstone experience is a two semester sequence of courses in which students design and implement a product or engineered system. The first course in the sequence, ME4015, introduces the product development process and stresses concept development and preliminary design. The subsequent course, ME4016, focuses on detail design, implementation, and testing. The courses are taught in multiple sections with each section assigned a specific team project. Enrollment in each section ranges from 5 to 30 students depending on the scope of the project. These projects generally involve only mechanical engineering students, although some of the larger projects such as the Hybrid Electric Vehicle Team and the Autonomous Vehicle Team involve students from other engineering disciplines. This paper describes experiences with a senior design project that is multi-disciplinary in a very broad sense, involving students from mechanical and electrical engineering as well as students from architecture, industrial design, and building construction. These students worked together to construct a solar powered house for participation in the Solar Decathlon competition. 
The Solar Decathlon is a student competition sponsored by the Department of Energy that challenges student teams to design and build grid independent solar powered houses and transport the houses to the National Mall in Washington, DC ${ }^{2}$. On the Mall, the teams participate in a two week display and competition. Fourteen teams participated in the first Solar Decathlon competition which was held from September 26 to October 6, 2002. The houses were judged in ten contests including:

- Design and livability

- Design presentation and simulation

- Graphics and communication

- The comfort zone

- Refrigeration
- Hot water

- Energy balance

- Lighting

- Home business

- Getting around

The houses were judged using both objective evaluations based on monitored data for the houses and subjective evaluations based on reviews by panels of judges.

This paper describes the ME4015/ME4016 course sequence as implemented for mechanical engineering students participating in the Solar Decathlon project. The mechanical engineering students were responsible for the design and implementation of the energy collection and energy distribution systems including:

- Solar PV,

- Solar thermal,

- Space conditioning,

- Water heating,

- Lighting, and

- Electrical distribution.

The design and implementation of these systems was used to teach an engineering design methodology, teamwork skills, and professionalism. The coordination of the engineering efforts with the architectural design provided students the opportunity to interact with students who had a different educational background, a different value system, and a different approach to the design process.

This paper describes the course design, the prior educational background of the students, and the instructional activities. Results in the form of student responses to survey questions illustrate the degree to which the educational objectives were achieved and highlight the benefits of a multidisciplinary project.

\section{COURSE Design}

The objectives of the ME4015/4016 course sequence are to provide students with experience in design and implementation of an engineering system, to develop teamwork skills, and to encourage professional development in areas such as engineering ethics, project management, and communication skills. These objectives are similar to those established for other engineering capstone courses ${ }^{1,3,4}$. The mechanical engineering faculty at Virginia Tech consider it particularly important that the student project result in a design that is actually realized in some form so that students experience the challenge and satisfaction of translating their designs into 
reality. In the 2001-2002 academic year, there were a total of 20 projects including industry sponsored projects, entries in student design competitions, and projects related to faculty research.

\section{A. Educational Objectives}

The general goals of teaching a design methodology, developing teamwork skills, and encouraging professional development were translated into nine specific educational objectives as detailed in Table 1. These nine objectives were common to all of the sections of the capstone course. Two additional objectives were established for the Solar Decathlon project to take advantage of the unique opportunities involved in working with students from diverse academic backgrounds. These objectives build on the foundations established in the students' prior coursework.

\section{B. Prior Educational Experience}

Students participating in the ME4015/4016 sequence are seniors in mechanical engineering. Engineering courses that are required prior to the capstone design course are summarized in Table 2. The sophomore design course, ME2024, introduces students to a design methodology

Table 1. Educational Objectives for the Engineering Design and Project Realization Course

1. Design mechanical and/or thermal systems using engineering, science, and mathematical methodologies.

2. Design experiments to test the performance of machine systems and components used in the product design.

3. Establish customer needs, design alternatives, evaluate alternative in a contextual sense, and select the most appropriate design alternative.

4. Design systems in a team environment where many disciplines are used and needed to complete the design.

5. Identify and develop multiple solutions to the posed open-ended problems.

6. Identify and respond properly to ethical problems and responsibilities.

7. Make effective presentations in front of technical- and marketing-type audiences.

8. Use library and Internet sources for the continued education and life-long learning needed to survive in an industrial setting.

9. Use modern engineering tools such as Matlab, MathCAD, Ideas, and other mathematical or finite element tools.

10. Develop an understanding and appreciation for different approaches to the design process (specific Solar Decathlon course objective).

11. Develop an understanding of the critical success factors for multi-disciplinary projects (specific Solar Decathlon course objective). 
Table 2. Engineering coursework required prior to the capstone course

\begin{tabular}{|l|l|}
\hline Freshman & Engineering fundamentals \\
\hline Sophomore & Introduction to design \\
& Computer applications in mechanical engineering \\
& Manufacturing processes \\
& Static/Dynamics/Material Science/Deformables \\
& Introduction to thermal fluid engineering \\
\hline Junior & Electrical circuits/Industrial electronics \\
& $\begin{array}{l}\text { Dynamics/Controls/Vibrations } \\
\text { Thermodynamics/Heat transfer/Fluid mechanics } \\
\end{array}$ \\
\hline
\end{tabular}

that emphasizes:

- Establishing customer needs

- Developing product specifications

- Creating a variety of conceptual designs

- Establishing and using criteria to select the best design

The junior level courses develop the analytical skills that are employed in the senior design course. For example, in the Solar Decathlon project, many of the junior level courses had direct application. Concepts from the heat transfer and thermodynamics courses were applied to the calculation of the heating and cooling requirements for the house and the design of the solar thermal heating system. Approaches developed in fluid dynamics were useful for sizing pipe, calculating pressure drop, and selecting pumps for the solar thermal and domestic water systems. Some of the team members applied knowledge from their strength of materials and mechanical design classes to the development of concepts for the photovoltaic array support.

By the time they reach the senior design course, mechanical engineering students are firmly indoctrinated in an analytical approach to problem solving in which they:

- Define the problem and determine given information

- Apply physical laws and material properties

- Solve the problem and interpret results

Engineering students are typically much less comfortable with open ended problems in which the problem statement and given information are unclear (e.g. design a house). One of the goals of the capstone course is to help students learn to address open ended design problems using a design methodology and to help them recognize the role of their analytical skills in the overall design process.

While this paper focuses on the educational experiences of the engineering students, it is important to note the academic background of the architecture students since one of our goals was to encourage Solar Decathlon project team members to develop an appreciation for other approaches to design. In the first years, architecture students take courses in design principles and procedures. In their junior year, they focus on structure, building technology, and health and safety issues. In the final years, students focus on specific areas such as design, building systems, sustainability, etc. and choose coursework to support their interests. A defining aspect of the architectural curriculum is the design studio class. In studio classes, architecture students 
are assigned projects which they explore, with faculty guidance, using a variety of design technologies (computer programs, modeling, photography, etc.).

\section{Expected Gains in Knowledge and Skills}

The ME4015/4016 sequence is designed to yield gains in knowledge and skills that extend the students prior educational experience to achieve the educational objectives defined in Table 1 . Typically some specialized technical knowledge is gained but the most significant gains include a deeper understanding of the design process, development of teamwork skills, and professional development.

For the Solar Decathlon project team, the specialized technical knowledge that the students were expected to acquire included:

- Evaluation of solar radiation characteristics

- Application of power electronic equipment (inverters, charge controllers, etc.)

- Electrical code compliance

More generally, to meet objectives $1-3$, the students are expected to enhance their ability to apply an orderly, structured design methodology similar to that introduced in their sophomore course. They are expected to develop an appreciation for the roles of creativity (objective 5) and analysis (objective 1) in this process and to recognize that design often does not follow a direct path but rather one of iterative improvement. The students are also expected to develop the ability to work effectively in teams. While students likely have prior experience studying and working together on homework assignments with friends, they are expected to learn to work effectively with other students with whom they may have little in common other than a shared project goal. Finally, students are expected to achieve significant gains in their ability to communicate their ideas in written and presentation form.

In summary, gains in knowledge and skills in the senior design sequence are expected to integrate and enhance the student's design and analytical skills and to help complete the educational experience by teaching the "implicit curriculum" which Waitz and Barret ${ }^{5}$ and Pimmel $^{3}$ describe as "the things we expect our students to learn but never teach in a course."

\section{INSTRUCTIONAL ACTIVITIES}

The gains in knowledge and skills described in the preceding section were pursued through a combination of in-class activities and assignments.

\section{A. In-class activities}

The ME4015/4016 class sessions included instructional activities, design team presentations, and group discussions. A schedule of classroom activities for the first semester course, ME4015, is presented in Table 3. The second semester course ME4016 consisted primarily of design team presentations, group discussions, and independent work required to implement the design. 
Table 3. Schedule of in-class activities for ME4015

\begin{tabular}{|l|c|c|}
\hline Topic & $\begin{array}{c}\text { Session } \\
\text { Type }\end{array}$ & $\begin{array}{c}\text { Number of } \\
\text { Sessions }\end{array}$ \\
\hline Design methodology & $\mathrm{L}$ & 2 \\
\hline Team dynamics & $\mathrm{L}$ & 1 \\
\hline Communication skills & $\mathrm{L}$ & 1 \\
\hline Creation and protection of intellectual property & $\mathrm{L}$ & 2 \\
\hline Engineering ethics & $\mathrm{L}$ & 1 \\
\hline Project management & $\mathrm{L}$ & 1 \\
\hline Solar energy basics & $\mathrm{L}$ & 5 \\
\hline Product development & $\mathrm{GA}$ & 5 \\
\hline Design presentation & $\mathrm{SP}$ & 3 \\
\hline Project coordination & $\mathrm{GA}$ & 10 \\
\hline Energy collection and distribution technology & $\mathrm{L} / \mathrm{SP}$ & 7 \\
\hline Note: L lecture & & \\
$\quad \begin{array}{l}\text { GA }=\text { group activity } \\
\text { SP }=\text { student presentation }\end{array}$ & & \\
\hline
\end{tabular}

The first semester course provided one 50-minute group lecture and two 75-minute project team meetings per week. During the group lecture, all of the senior project teams met together in a single lecture hall. Lectures were conducted by mechanical engineering professors and invited speakers with expertise in specific areas. The lectures topics fell into two categories: design methodology and professional practice. Design methodology lectures addressed the design process, ideation, and design documentation using an engineering logbook. Professional practice lectures focused on oral and written communication skills, project management, and engineering ethics. Information presented in the lectures was reinforced through the activities of the individual project teams.

For the Solar Decathlon project, team meetings included lectures addressing fundamentals of solar energy applications, meetings to coordinate activities among the mechanical engineering team members, coordination meetings with the architectural team, and design presentations. For the first five weeks of the ME4015 semester, one weekly project team meeting was focused on solar energy basics and highlighted material from the first two chapters of the text by Duffie and Beckman $^{6}$. During this period the other weekly meeting focused on the early stages of product development including project planning, development of a project mission statement, and identification of customer needs. The mission statement prepared by the students is presented in Table 4.

During the remainder of the semester, the class time was divided equally between class discussions led by the instructor, technical presentations by students, and project coordination meetings. Students were asked to prepare brief presentations to introduce other students to specific areas of technology (e.g. photovoltaic arrays, storage batteries, inverters, etc.) that were important to the Solar Decathlon project. These presentations helped both the presenter and the 
Our mission as Senior Mechanical Engineering students at Virginia Polytechnic Institute and State University, is to enhance our education through the design and construction of a competitive entry for the Solar Decathlon that uses efficient technology powered exclusively by solar energy to provide an architecturally appealing, comfortable living and working environment.

class learn about the technology and also helped the presenters to become comfortable with making brief relatively informal presentations. In addition, the student team which consisted of seventeen mechanical engineering students was divided into groups to focus on specific subsystems of the design including:

- Photovoltaic array and electrical storage and distribution systems

- Solar thermal collectors and water distribution systems

- Heating, ventilating, and air conditioning system

- Energy modeling, controls, and appliance selection

The students presented weekly updates of the progress related to their particular sub-system. Formal presentations were made at mid-semester and at the end of the semester. The mid-term presentation was part of a coordination meeting with the architectural team. The final presentation was made in a formal conference setting and was delivered to audiences including architectural team members, other faculty members, and representatives from outside companies.

The second semester of the project course focused on design implementation and the student team worked more independently. During this semester, the course provided two 75-minute sessions per week. The first weekly session was used for meetings between the individual groups (e.g. solar PV, solar thermal, etc.) and the instructor. During these sessions, the instructor provided technical advice and coaching to assist the group in the implementation of their aspect of the design. The second weekly ME4016 session was devoted to team meetings to assess progress and to coordinate the efforts of the groups. During this semester, team members delivered informal presentations highlighting key technical or coordination issues. They also delivered a more formal mid-term presentation as part of an overall team meeting with architecture students. In addition, in conjunction with the architecture students, they prepared a Solar Decathlon display and demonstration as part of Virginia Tech's Earth Day activities. At the end of the semester, they made a formal presentation of the design and its implementation to an audience that included other faculty and representatives from outside companies.

\section{B. Assignments}

In addition to their classroom activities, students completed a number of outside assignments that helped to achieve the educational objectives. These assignments included keeping logbooks, preparing progress reports, and preparing final reports.

Each student was required to keep an engineering logbook documenting the student's personal contribution to the design process. Documentation included descriptions of ideas and decisions, sketches, data, and references. This exercise was intended to help students organize their thoughts and activities. In addition, the logbook was prepared in a style that would help support

Proceedings of the 2003 American Society for Engineering Education Annual Conference \& Exposition 
a patent defense. A lecture on developing and patenting intellectual property provided background for this assignment. The logs were reviewed and graded three times during each semester.

In addition to the logs, each of the four groups submitted a weekly progress memorandum. For each submission, one group member wrote the memo and a second group member edited it. This gave the students experience with writing a business memo and with critically reviewing a document. The writing and editing assignments were rotated among group members and the students signed for their respective roles. The instructor graded, annotated, and returned the memos to the students.

In addition to preparing memos, students wrote final reports to develop their skills in preparing more comprehensive and thoroughly researched documents. These reports were graded, returned for re-writing, and graded again. In the process of making revisions, students reconsider their ideas and writing style and hopefully learn to think and write with greater clarity and focus.

\section{REsults}

\section{A. Educational objectives}

The success of the course sequence in achieving the first nine educational objectives was assessed through student surveys in which the students were asked to rate the extent to which each of the objectives was met. Achievement of the last two educational objectives was assessed through a somewhat more subjective approach in which students were questioned about their perceptions of engineering and architectural design and about critical success factors for multdiscipinary projects. Finally, students were asked to assess the ways in which their senior design project was different from other more academic design exercises that had been introduced in their courses.

A student survey assessing the first nine learning objectives was conducted at the end of each semester. Students were given the list of learning objectives presented in Table 1 and asked to rate the extent to which they felt the objective had been met on a scale of 1 to 4 as follows:

1. Objective not satisfied

2. Objective poorly satisfied

3. Objective mostly satisfied

4. Objective completely satisfied

Results from the student survey are presented in Figure 1 for both ME4015 and ME4016. The results suggest that from the student perspective, the educational objectives were mostly to completely satisfied in all areas except for the area of "design of experiments to test the performance." In the first semester, this area was not scheduled to be addressed and student responses are not reported in the figure (most students elected to omit a response to this question). In the second semester, product testing was a formal objective. However, time constraints prevented most of the groups from accomplishing more than rudimentary testing of their systems. Better scheduling by the students and the instructor would have permitted more time to be devoted to this important activity. 


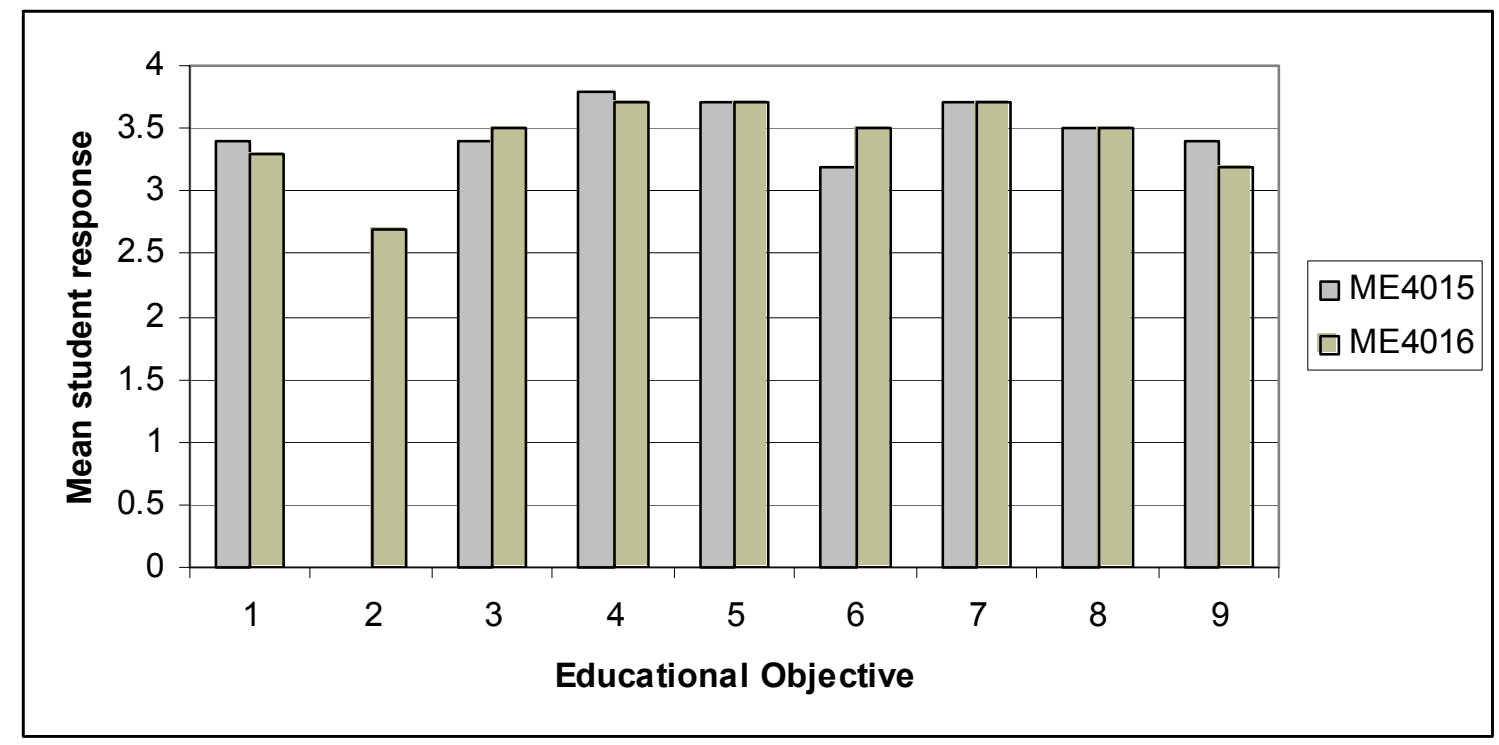

Figure 1. Student evaluation of achievement of education objectives.

The students expressed the most confidence that objectives 4, 5, and 7 were met. These objectives focused on teamwork, dealing with open ended problems, and presentation skills. Not surprisingly, these areas were given the most emphasis in the instructional activities. In addition, these were the activities in which all students participated and thus were consistently rated highly. Other objectives, such as application of computer tools, were rated highly by some students (presumably students who were most involved in activities such as energy simulation) but were not rated as well by other students.

Results documenting achievement of educational objectives for other sections of the senior design course were not systematically compiled during the 2001-2002 academic year when the Solar Decathlon project course was offered. During the following year, results from all sections were compiled but the wording of the objectives had changed slightly making direct comparison difficult. However, four of the stated objectives for fall semester 2002 were similar enough to allow comparison to the Solar Decathlon project. These objectives and the average responses are as follows:

- Establish customer needs

Overall average $($ fall 2002 $)=3.4 \quad$ Solar Decathlon $($ fall 2001 $)=3.4$

- Design systems in a team environment

Overall average $($ fall 2002 $)=3.4 \quad$ Solar Decathlon $($ fall 2001 $)=3.8$

- Identify and develop multiple solutions to the posed open-ended problems

Overall average $($ fall 2002 $)=3.8 \quad$ Solar Decathlon $($ fall 2001 $)=3.7$

- Make effective presentations

Overall average $($ fall 2002 $)=3.7 \quad$ Solar Decathlon $($ fall 2001 $)=3.7$ 
Responses for the Solar Decathlon project were similar to the averages for other projects in all areas except for the objective of learning to design in a team environment. The Solar Decathlon project participants reported a noticeably higher achievement of this objective. This suggests that the multi-disciplinary environment did contribute to the development of team skills. However, a more rigorous study would be required to draw firm conclusions.

Achievement of each of the last two educational objectives was assessed through an iterative survey method designed to determine the thoughts of course graduates regarding:

- Their own approach to design as contrasted with that of their colleagues in architecture and

- The key success factors for a multi-disciplinary team project.

The survey method was a two step process, similar to the Delphi method, designed to build consensus while preventing students with strong opinions from dominating the process. Students were asked to supply short answers via email to the list of questions presented in Table 5. The answers were compiled anonymously into a single document that listed each question and all responses to that question. In the final class session, the students were given the compilation of responses and asked to review it. They were then asked to answer each of the questions again after considering the responses of their classmates. Tables 6 to 12 summarize the most common student responses to each question and present some of the more insightful comments verbatim.

As the responses in Table 6 indicate, students completing the project course had a strong sense that engineering design was a structured process that involved identification of needs, problem definition, ideation, analysis, and selection from among alternatives. They recognized that design is an iterative process as a design concept evolves from an idea to implementation. They also recognized the importance of timeliness in completion of a project. As noted below, one of their major points of contention with the architecture team members was the perception that the

\section{Table 5. Questions to assess student perceptions of engineering and architectural design} approaches and team project success factors

1. Based on your experiences with this project, how do engineers approach the design process?

2. What can engineering students learn from the architectural approach to design?

3. Based on your experience with this project, how do architects approach the design process?

4. What can architecture students learn from the engineering approach to design?

5. What are the key factors that are essential to the success of a team based project such as your senior design project?

6. What additional factors are essential for success when the project, like your senior design project, involves diverse disciplines?

7. In what way was your senior design project different from design exercises presented in your coursework?

Proceedings of the 2003 American Society for Engineering Education Annual Conference \& Exposition Copyright (C) 2003, American Society for Engineering Education 
Table 6. Student perceptions of engineering design approach

Common elements of the engineering design approach include:

- Identification of needs and problem definition

- Sub-division of problem into elements

- Ideation followed by analysis and selection of a solution

- Iteration

- Emphasis on order and timeliness

Table 7. Student perceptions of possible improvements to engineering design approach

Key ideas that engineering students can learn from architects:

- Be more creative - place more emphasis on exploration and imagination

- Appreciate aesthetic issues and put more emphasis on product form

- More emphasis on physical model building - good for iteration

- Communicate

- Consider alternatives and keep an open mind

Quotes:

- "Get outside the box and work there!"

- "Be mindful of aesthetics - the point of technology is to improve quality of life and sustainability."

- "Be more aware of things that are 'artsy' and may not make sense."

architects wanted to keep exploring ideas without considering the impact on the project schedule. The engineering team, members, perhaps because of their impending graduation, were more comfortable with including the constraints of time on the design process and with making compromises where necessary. On the other hand, as indicated by the responses in Table 7, the engineering team members recognized many positive characteristics of the approach taken by the architecture students. They admired their creativity and willingness to explore alternative design solutions. The engineering students also recognized that a user values a product not only for its functionality but also for its aesthetic qualities. Finally, by interacting with the architecture team, engineering students gained an appreciation for the importance of "building something and seeing if it works." This approach was illustrated through the physical models that the architects constructed to illustrate their design ideas. In summary, the design project helped engineering students understand a design methodology while interaction with team members from other disciplines helped to highlight the importance of elements of the methodology such as ideation and creativity as well as prototyping.

As indicated in Table 8, engineering students recognized some commonality between the approaches of engineers and architects with the distinction that architects tend to be guided more by issues of form, aesthetics, and feeling while engineers placed their emphasis on structure and order. Overall, the student responses highlight an important distinction between the approaches taken by the engineering and architecture teams. The engineering team was focused on applying a structured design process to meet someone else's needs (as expressed in the contest rules or the customer needs survey) as quickly and efficiently as possible. The architecture students tended to place more emphasis on using the design process to make a statement of their personal beliefs 
Table 8. Student perceptions of architectural design approach

Common elements of the architectural design approach include:

- Approach is similar to engineering but with a stronger emphasis on aesthetics

- Guided by innovation, feeling, and impressions

- Favor form over function

- Emphasis on physical prototypes

- Exhaustive search of possibilities

Quotes:

- "They try for form follows function but without understanding function they sometimes wander astray."

Table 9. Student perceptions of possible improvements to architectural design approach

Key ideas that architecture students can learn from engineers:

- Recognize practical limitations

- Be more open to advice (e.g. from engineers)

- Put more emphasis on function

- Conduct a more orderly, objective, and efficient search for solutions

- Make decisions after research not before

- Select a solution and stick with it - move forward

- Respect deadlines

Quotes:

- "Moderate their emphasis on innovation with some emphasis on proven solutions."

- "Their thinking outside the box is good but they need to keep it realistic and make their deadlines."

- "We all needed to learn to be open to each other's ideas."

(e.g. "A solar home should celebrate the sun's light"). Through their responses in Table 9, the engineering students felt that the architecture team members could benefit from a more orderly approach to design, a stronger emphasis on deadlines, and a greater emphasis on product functionality. These responses basically reflect what the engineers consider to be the core values of their own approach to design.

The responses presented in Tables 10 and 11 indicate that the students recognized the importance of communication, flexibility, organization, and time management to any project. They saw the issues of communication and leadership as particularly important in multidisciplinary projects. For this project, architects and engineers tended to work separately and then meet to coordinate their efforts. Student responses suggest that future student projects could be improved by developing a team structure focused on closer integration of the disciplines. Finally, the responses in Table 12 suggest that students recognized the unique and valuable contribution of their project experience to their overall education. 
Table 10. Critical success factors for team projects

Critical success factors for team projects include:

- Communication

- Patience and flexibility

- Clear timeline

- Dedication to common goals

- Cooperation and compromise

- Organization and a clear chain of command

Quotes:

- "It requires comprise from everyone - you aren't immune."

Table 11. Additional requirements for success in a multi-disciplinary environment

In addition to items in Table 10, multi-disciplinary projects require:

- An appreciation of the way other disciplines think

- Strong leadership and a common direction

- Delegation of responsibility

- Communication, patience, and compromise

- Common deadlines

- Interdisciplinary working groups

Quotes:

- "Periodic meetings are OK but it would be best if engineers and architects worked immediately with each other every day."

Table 12. Differences between senior design project and prior coursework

The Solar Decathon senior project was different from prior educational experience because:

- Design is taken to realization

- Students are responsible to themselves and their team members

- Students worked with other disciplines

- More iteration is required to reach a final solution

- Design elements had to be procured - required considering cost, availability, etc.

- Leadership is more important

- Constructability must be considered

Quotes:

- "I have never iterated this much before!"

- "It is not all just numbers."

- "More responsibility because you don't want to make junk." 
The results presented here suggest that engineers and architects can learn from each other's approach to the design process. One way to facilitate this learning would be through the formation of cross-disciplinary teams. While the project was multi-disciplinary, much of the work was accomplished by engineers working on tasks that were perceived to be "engineering tasks" and architects working on "architecture tasks". The students learned multi-disciplinary teamwork by coordinating their tasks at the interfaces. The learning process could be enhanced by assigning both engineers and architects to work on a particular task regardless whether the task would be traditionally assigned to a specific discipline. This approach is supported by the student quote from Table 11, "Periodic meetings are OK but it would be best if engineers and architects worked immediately with each other every day."

The learning process could also be enhanced if team dynamics and interaction were assessed periodically during the project. Assessment tended to focus on outcomes instead of processes. In other words, the assessment techniques tended to focus on what the team accomplished not how the team functioned. The survey conducted at the end of the course provided valuable information for understanding how the students interacted and how they perceived the activities of their teammates. If this survey or one like it been conducted earlier in the process, the team members could certainly have benefited from the results and the ensuing discussion.

While the results presented here provide considerable insight regarding the success of the course in achieving its objectives, improvements in course assessment techniques would be helpful. For example, final presentations were attended by representatives of companies that helped to sponsor the project and by architecture faculty. Input from these individuals was used to help assign the student grades. However, these attendees were not aware of the specific educational objectives and thus not prepared to critically assess the success of the course. These outside reviewers could be provided with a description of the course objectives prior to the midterm and final presentations and then given the opportunity to question the students following their presentations. The reviewers could then provide a better assessment of the success of the course and would be better prepared to suggest improvements. Also, in future offerings of this project course, mechanical engineering faculty members teaching separate sections could agree to attend each other's classes for mid-term and final presentations. Since the engineering faculty members are very familiar with the course objectives, their review of the students' work would be very helpful in assessing and improving the course.

Results presented here suggest that the Solar Decathlon project course was successful in achieving most of the educational objectives for the course. In particular, students developed a solid understanding of the engineering design process as well an appreciation for other design approaches. They also seemed to develop a particularly strong understanding of the need for communication, flexibility, and organization in a team environment. Improvements in the course, such as formation of cross-disciplinary teams and periodic evaluation of team performance and interaction, could help to further improve the success of the course in meeting its objectives. In addition, better assessment techniques could help to identify areas for improvement. 


\section{B. Project results}

The Solar Decathlon competition took place from September 26 to October 6, 2002 on the National Mall in Washington, DC. The students in the senior design course were scheduled to graduate prior to the competition and, in fact, prior to completion of the structure of the house by the architecture team. The team thus decided to complete the engineered systems for the house in modules that could be easily installed in the house as the house structure progressed. By the end of the second semester, the team had:

- Completed an energy simulation model of the house using a variant of the DOE2 software,

- Designed and built a water supply module to provide water to the house from storage tanks

- Designed and built a solar thermal system module for circulating water through the collectors and storage tank

- Designed and built an electrical distribution module for receiving PV power, controlling battery state-of-charge, providing ground-fault and overcurrent protection, and inverting DC power to AC power,

- Selected and procured energy efficient appliances for the house

- Selected and procured a split-system console heat pump and an air-to-air heat exchanger for installation in the house.

Between May and September, engineering student volunteers worked with the architecture team to put the various systems in place. Students from the fall 2003 senior design course were also instrumental in completing work on the house.

The Solar Decathlon competition was well attended with thousands of people visiting during the weekend periods when the houses were open to the public. The Virginia Tech entry received first place awards for Design Presentation and Simulation and for the Getting Around competition in which they drove over 400 miles using excess energy from the PV panels. The team also won the BP Solar Award for Innovation - Creating breakthrough solutions. Overall, the team's entry placed fifth in the competition.

In summary, the Solar Decathlon senior design project provided students the opportunity to expand their knowledge, learn a design methodology, develop teamwork and communication skills, and develop a deeper understanding of their own approach to design as well as an appreciation for alternative approaches. The students achieved these objectives while designing and building an award winning solar house.

\section{Conclusions}

Design projects help students learn to address open ended problems and to appreciate their analytical skills as a part of the overall design process. In contrast, most other undergraduate engineering courses focus on analytical efforts in which the student is provided with a complete and thorough problem statement. Moreover, the analysis is often designed to answer a question instead of make a decision. Students typically have little experience in addressing open ended design issues. A design project challenges students to create a design instead of analyze a design. This may involve multiple cycles of ideation, problem formulation, analysis, and 
decision making. Students must learn to deal with multiple, often conflicting objectives. In order to meet these challenges, students must learn to work together as a team and to communicate their ideas.

Multi-disciplinary projects require particular attention to communication since the various disciplines often approach problems with different values and different design methodologies. By encouraging interaction between people from different academic backgrounds, multidisciplinary projects can lead students to both a deeper understanding of their own approach to design and an appreciation for alternative approaches.

Results from this multi-disciplinary project course suggest that it was successful in developing students' design capabilities, improving their teamwork skills, and encouraging an understanding and appreciation for the design process. Improvements in the course such as the development of cross-disciplinary teams and the periodic assessment of team interactions may lead to even greater success in achieving the educational objectives. In addition, improved assessment techniques, such as course evaluation by other faculty and outside reviewers can help to identify additional areas for improvement.

\section{ACKNOWLEDGEMENT}

The VTSolar entry in the 2002 Solar Decathlon Competition was made possible by the efforts of the project organizers at the Department of Energy ${ }^{2}$, numerous project sponsors ${ }^{7}$, faculty and staff in the College of Engineering and the College of Architecture and Urban Studies, Prof. Robert Schubert who organized the team of faculty advisors, and the many student participants ${ }^{7}$.

\section{REFERENCES}

1. Todd, R.H., et al., "A Survey of Capstone Engineering Courses in North America," Journal of Engineering Education, vol. 84, no. 2, 1995, pp. 165-174.

2. Office of Energy Efficiency and Renewable Energy, U.S. Department of Energy, The Solar Decathlon, available on-line: www.eren.doe.gov/solar_decathlon, accessed January 15, 2003.

3. Pimmel, R., "Cooperative Learning Instructional Activities in a Capstone Design Course," Journal of Engineering Education, vol. 90, no. 3, 2001, pp. 413-421.

4. Dutson, A.J. et al., "A Review of Literature on TEachnig Engineering Design Through Project-Oriented Capstone Courses," Journal of Engineering Education, vol. 86, no. 1, 1997, pp. 17-28.

5. Waitz, I.A. and E.C. Barret, "Integrated Teaching of Experimental and Communication Skills to Undergraduate Aerospace Engineering Students," Journal of Engineering Education, vol. 86, no. 3, 1997, pp. 255-262.

6. Duffie, J.A. and W.A. Beckman, Solar Engineering of Thermal Processes, New York: John Wiley \& Sons, Inc., 1991. 